DOI: https://doi.org/10.24127/ajpm.v10i4.4369

\title{
KEMAMPUAN PENALARAN MATEMATIS SISWA DALAM MENYELESAIKAN SOAL LITERASI MATEMATIKA KONTEKSTUAL
}

\author{
Rajab Vebrian ${ }^{1}$, Yudi Yunika Putra ${ }^{2 *}$, Sari Saraswati ${ }^{3}$, Tommy Tanu Wijaya ${ }^{4}$ \\ 1,2* Pendidikan Matematika, Universitas Muhammadiyah Bangka Belitung, Indonesia \\ ${ }^{3}$ Pendidikan Matematika, Universitas Hasyim Asy'ari Tebuireng Jombang, Indonesia \\ ${ }^{4}$ Department Mathematics and Statistics, Guangxi Normal University, China \\ *Corresponding author. Universitas Muhammadiyah Bangka Belitung, Indonesia \\ E-mail: $\quad$ rajab.vebrian@unmuhbabel.ac.id ${ }^{1)}$ \\ yudi.yunikaputra@unmuhbabel.ac.id ${ }^{2 *}$ \\ sarisaraswati7@gmail.com $^{3)}$ \\ tanuwijayat@gmail.com $^{4)}$
}

Received 30 October 2021; Received in revised form 08 December 2021; Accepted 23 December 2021

\begin{abstract}
Abstrak
Literasi matematika penting dimiliki seseorang karena merupakan kemampuan untu bernalar secara matematis dan untuk merumuskan, menerapkan, serta menafsirkan pemecahan masalah dalam berbagai konteks sehari-hari. Sesuai dengan studi PISA yang menilai siswa berumur 15 tahun dengan usia siswa SMA maka penelitian ini bertujuan untuk mengetahui kemampuan penalaran siswa SMA dalam menyelesaikan soal literasi matematika. Metode yang digunakan dalam penelitian ini adalah deskriptif kualitatif. Subjek penelitian sebanyak 22 siswa kelas X salah satu SMA Swasta di Pangkalpinang. Teknik pengumpulan data adalah tes tertulis dan wawancara. Instrumen tes berupa 10 butir soal literasi matematis hasil pengembangan yang memenuhi kriteria valid, praktis, dan efek potensial terhadap kemampuan penalaran siswa. Soal yang dikembangkan menggunakan konteks Bangka Belitung. Hasil jawaban siswa dinilai berdasarkan rubrik penskoran melalui indikator kemampuan dasar matematika penalaran dan argument. Sedangkan wawancara dilakukan kepada 6 siswa yang diambil dengan teknik purposive sampling yang memiliki kemampuan penalaran tinggi, sedang, dan rendah. Data wawancara digunakan untuk menggali lebih dalam mengenai kemampuan penalaran siswa saat menyelesaikan soal tersebut. Data dianalisis berdasarkan pada persentase indikator kemampuan penalaran matematis siswa yang meliputi reduksi data, penyajian data, dan penarikan kesimpulan/verifikasi. Dari hasil analisis diperoleh bahwa taraf penguasaan kemampuan penalaran siswa sangat rendah pada semua indikator. Pada indikator mengajukan dugaan, manipulasi matematika, menyusun bukti dan alasan mencapai taraf sebesar 42,88\% sedangkan pada taraf penguasaan indikator menarik kesimpulan dari pernyataan sebesar 41,36\%. Penyebab dari kesulitan siswa memunculkan kemampuan penalaran diantaranya siswa belum terbiasa menyelesaikan soal-soal yang menuntut kemampuan penalaran yang tinggi seperti pada soal-soal literasi matematika yang dikerjakan dan kurangnya penguasaan konsep matematika yang telah dipelajari sehingga sulit memunculkan kemampuan penalaran.
\end{abstract}

Kata kunci: Konteks; literasi; matematika; penalaran.

\begin{abstract}
Mathematical literacy is essential because it can reason mathematically and formulate, apply, and interpret problem-solving in various everyday contexts. Following the PISA study, which assessed students aged 15 years with the age of high school students, this study aims to determine the reasoning ability of high school students in solving mathematical literacy problems. The method used in this research was descriptive qualitative. The research subjects were 22 students of class $X$, one of the private high schools in Pangkalpinang. Data collection techniques were written tests and interviews. The test instrument consisted of 10 items of developed mathematical literacy questions that meet the criteria of being valid, practical, and potentially affecting students' reasoning abilities. The questions were developed using the Bangka Belitung context. The students' answers were assessed based on a scoring rubric through primary mathematical skills of reasoning and argument indicators. Meanwhile, interviews were conducted with six students using the purposive sampling technique with high, medium, and low
\end{abstract}


DOI: https://doi.org/10.24127/ajpm.v10i4.4369

reasoning abilities. Interview data were used to dig deeper into students' reasoning abilities when solving the problem. Data were analyzed based on the percentage of students' mathematical reasoning abilities indicators, including data reduction, data presentation, and concluding/verification. The analysis results found that students' reasoning abilities mastery was very low on all indicators. At the indicator proposing allegations, mathematical manipulation, compiling evidence and reasons, it reaches a level of $42.88 \%$, while at the level of mastery, the indicator concluded statements of $41.36 \%$. The causes of students' difficulties in bringing up reasoning abilities included students who were not accustomed to solving questions that required high reasoning abilities. For example, mathematical literacy questions that were done and lack of mastery of mathematical concepts that had been studied made it challenging to bring up reasoning abilities.

Keywords: Context; literacy; mathematics; reasoning.

This is an open access article under the Creative Commons Attribution 4.0 International License

\section{PENDAHULUAN}

Literasi matematika memiliki peranan penting untuk memahami kegunaan matematika dalam kehidupan sehari-hari (Putra \& Vebrian, 2019), membuat keputusan yang tepat sebagai warga negara yang membangun, peduli, dan berpikir (OECD, 2013), dan menjadi salah satu kunci untuk menghadapi masyarakat yang terus berubah (disrupsi) (Janah et al., 2019). Pentingnya kemampuan literasi matematika tidak serta merta diikuti siswa Indonesia dalam studi PISA (Programme for International Student Assessment), yang merupakan penilaian siswa umur 15 tahun yang dilakukan oleh OECD (organisation for economic co-operation and development). Pada penilaian PISA tahun 2018 membuktikan kemampuan literasi matematika siswa Indonesia masih dibawah rata-rata dibanding negara lain, siswa Indonesia berada pada posisi ke 73 dari 79 negara (OECD, 2019); (Putra \& Vebrian, 2019). Sedangkan hasil TIMSS menunjukkan siswa Indonesia berada pada posisi 45 dari 50 negara (Leksmono et al., 2019).

Sesuai dengan framework PISA 2018, ketiga proses matematika (merumuskan, menerapkan, dan menafsirkan) memiliki hubungan dengan kemampuan penalaran
(OECD, 2018) dan proses kognitif literasi matematika (numerasi) pada asesmen kompetensi minimum (AKM) dibedakan menjadi tiga level yaitu pemahaman, penerapan, dan penalaran (Duval, 2014). Kemampuan Penalaran dan Argumen merupakan salah satu kemampuan penting yang mendasari proses literasi matematika (Ayuningtyas et al., 2019); (Semilarski et al., 2019). Sehingga kemampuan penalaran memiliki peranan penting dalam meningkatkan kemampuan literasi matematika.

Kemampuan penalaran adalah salah satu kemampuan tingkat tinggi (HOTS) yang dianalisis pada studi PISA. Kemampuan ini sangat penting dalam menyelesaikan soal literasi matematika karena merupakan kemampuan dasar dalam menyelesaikannya (Ojose, 2011) serta melibatkan proses berpikir logis untuk mengeksplorasi dan menghubungkan bagianbagian dari masalah untuk membuat kesimpulan, memeriksa jawaban, atau memberikan pembenaran dari laporan/solusi yang diperoleh. Siswa perlu didorong untuk menguasai kemampuan penalaran matematis (Alim et al., 2020). Kemampuan tersebut dibutuhkan siswa untuk menghadapi masa depan dan mengikuti perkembangan dunia kerja. 
DOI: https://doi.org/10.24127/ajpm.v10i4.4369

Literasi matematika (numerisasi) dalam Assesmen Kompetensi Minimum (AKM) merupakan proses kognitif bernalar dengan konsep matematika untuk menyelesaikan masalah bersifat non rutin (Hendriana et al., 2017); (Schoevers et al., 2020). Aspek penting dari literasi matematika yaitu matematika terlibat dalam memecahkan masalah yang ditetapkan dalam konteks, konteksnya yaitu aspek dunia individu dimana masalah ditempatkan (OECD, 2018).

Dalam meningkatkan kemampuan penalaran siswa perlu dibiasakan dengan soal-soal yang mengukur kemampuan tingkat tinggi (High Order Thinking Skill) yaitu berupa soal non rutin dan kontekstual dalam pembelajaran (Trajuningsih, 2015); (Putra et al., 2016a).

Dengan mengerjakan soal kontekstual membantu siswa dalam mensituasikan matematika kedalam konteks (Putra et al., 2016b) dan memberikan stimulus kepada siswa untuk berpikir kritis menggunakan penalaran sendiri dalam penyelesaiannya (Putra et al., 2016b) sebab matematika itu sendiri digunakan untuk memecahkan masalah di kehidupan sehari hari (Fachrudin et al., 2019), memperkuat dan mengembang-kan sains dan berhubungan dengan perkembangan teknologi sampai hari ini (Hahn, 2020); (Schoevers et al., 2020). Permasalahan literasi matematika sangat baik apabila menggunakan permasalahan kontekstual yang dekat dengan kehidupan siswa dan saat siswa menyelesaikan masalah tersebut dapat dianalisis bagaimana siswa mengeksplorasi pengetahuan baru untuk mendukung dan mendorong kemampuan penalaran matematis siswa.

Kemampuan tersebut harus dilatih sejak dini agar dapat meningkat secara signifikan. Sedangkan kenyataan di lapangan, masih banyak guru yang hanya fokus pada nilai siswa dengan menggunakan kemampuan yang seadanya dan terbatas (Dewi et al., 2020);(Wijaya et al., 2020). Seorang pendidik harus mempunyai kemampuan mathematical dan pedagogical yang tinggi agar dapat membantu siswa meningkatkan kemampuan penalaran matematis secara efektif (Wijaya et al., 2021). Karena Kemampuan penalaran matematika adalah kemampuan yang dibutuhkan siswa untuk menganalisis situasi baru, membuat asumsi yang logis, menjelaskan ide dan membuat kesimpulan (Amir-Mofidi et al., 2012).

Tujuan dari penelitian ini didapatkan data tentang kemampuan penalaran siswa SMA dalam menyelesaikan soal literasi matematika. Sehingga dapat menjadi dasar dan informasi untuk penelitian selanjutnya dalam menginterasikan pembelajaran matematika dengan konteks sehari-hari siswa di dalam kelas dan mendorong siswa untuk meningkatkan kemampuan penalaran matematis serta memotivasi mereka untuk dapat menyelesaikan soal-soal kontekstual dengan tipe literasi matematis.

\section{METODE PENELITIAN}

Deskriptif kualitatif merupakan jenis penelitian yang digunakan dalam penelitian ini. Subjek penelitian ini adalah siswa kelas $X$ SMA Muhammadiyah Pangkalpinang yang berjumlah 22 siswa. Meskipun penelitian ini dilaksanakan saat kondisi pandemi Covid-19, penelitian tetap dilakukan secara tatap muka dengan mematuhi protokol kesehatan dengan cara membagi subjek menjadi 2 ruangan dengan jumlah masing-masing ruangan 11 siswa. Pemilihan subjek kelas $\mathrm{X}$ karena rata-rata berumur 15 tahun yang 
DOI: https://doi.org/10.24127/ajpm.v10i4.4369

sesuai dengan studi PISA yaitu mengukur kemampuan literasi matematika siswa berumur 15 tahun.

Teknik pengumpulan data menggunakan tes tertulis dan wawancara. Tes tertulis digunakan untuk mengetahui kemampuan penalaran matematis tertulis siswa, dan wawancara digunakan untuk informasi mendalam terkait kemampuan penalaran matematis siswa. Tes yang digunakan sebanyak 10 soal literasi matematika model PISA hasil penelitian pengembangan menggunakan konteks Bangka Belitung yang telah memenuhi kriteria valid, praktis, dan memiliki efek potensial terhadap kemampuan penalaran siswa. Valid berdasarkan masukan dan komentar 2 orang pakar literasi matematika, kepraktisan berdasarkan komentar subjek small group, dan efek potensial terhadap kemampuan literasi matematika berdasarkan hasil analisis data pada tahap field test.

Tes tertulis diberikan kepada semua subjek sedangkan wawancara diberikan kepada 6 subjek dimana masing-masing terdiri dari 2 subjek dengan kriteria kemampuan penalaran tinggi, sedang, dan rendah. Setelah siswa menyelesaikan soal, dilakukan analisis hasil tes kemampuan penalaran matematis siswa berdasarkan indikator kemampuan penalaran pada Tabel 1 .

Tabel 1. Rubrik penilaian kemampuan penalaran matematis

\begin{tabular}{clcl}
\hline No & \multicolumn{1}{c}{ Indikator } & Skor & \multicolumn{1}{c}{ Kriteria } \\
\hline 1 & Mengajukan & 0 & Tidak dapat mengajukan dugaan \\
& dugaan & 1 & Mengajukan dugaan dengan tidak benar \\
& & 2 & Mengajukan dugaan namun tidak lengkap \\
& & 3 & Mengajukan dugaan dengan benar dan lengkap \\
2 & Manipulasi & 0 & Tidak dapat memanipulasi matematika \\
& matematika & 1 & Memanipulasi matematika dengan tidak benar \\
& & 2 & Memanipulasi matematika namun tidak lengkap \\
& & 3 & Memanipulasi matematika dengan benar dan lengkap \\
3 & Menyusun bukti & 0 & Tidak dapat menyusun bukti memberikan alasan \\
& atau memberikan & 1 & Menyusun bukti, memberikan alasan tidak benar \\
& alasan & 2 & Menyusun bukti, memberikan alasan tidak lengkap \\
& & 3 & Menyusun bukti, memberikan alasan benar dan lengkap \\
& Menarik & 0 & Tidak dapat menarik kesimpulan dari pernyataan \\
& kesimpulan dari & 1 & Menarik kesimpulan dari pernyataan tidak benar \\
& pernyataan & 2 & Menarik kesimpulan dari pernyataan tidak lengkap \\
& & 3 & Menarik kesimpulan dari pernyataan benar dan lengkap \\
\hline
\end{tabular}

Data dianalisis berdasarkan pada persentase semua indikator kemampuan penalaran matematis siswa. Selanjutnya data dikonversikan seperti pada Tabel 2.

Tabel 2. Kualifikasi kemampuan penalaran matematis siswa

\begin{tabular}{ccc}
\hline No & Taraf Penguasaan $(\%)$ & Kriteria \\
\hline 1 & $86-100$ & Sangat Tinggi \\
2 & $76-85$ & Tinggi \\
3 & $60-75$ & Sedang \\
4 & $55-59$ & Rendah \\
5 & $0-54$ & Sangat Rendah \\
\hline
\end{tabular}

Analisis data mengacu pada model (Miles \& Huberman, 1992) yang meliputi: reduksi data, penyajian data, dan penarikan kesimpulan/verifikasi. Reduksi data berdasarkan hasil tes tertulis dan wawancara berdasarkan indikator kemampuan penalaran matematika siswa yang bertujuan untuk mempermudah dalam memilih data yang sesuai. Penyajian data tes tertulis dan wawancara berdasarkan indikator 
DOI: https://doi.org/10.24127/ajpm.v10i4.4369

kemampuan penalaran siswa yang bertujuan agar data yang disajikan lebih mudah dipahami, serta penarikan kesimpulan tentang kemampuan penalaran matematika siswa dalam menyelesaikan soal literasi matematika. Contoh soal literasi matematika dapat dilihat pada Tabel 3.

Tabel 3. Soal literasi matematika

\begin{tabular}{ll}
\hline No Butir & \multicolumn{1}{c}{ Bunyi Soal } \\
\hline 1 & Wisma Ranggam atau sebelumnya \\
dikenal sebagai "Pesanggrahan \\
Muntok" berada di tepi jalan Kota \\
Muntok Provinsi Kepulauan \\
Bangka Belitung. Bekas-bekas \\
keramaian zaman dulu masih \\
terlihat, yang ditandai beberapa \\
bangunan kuno berdinding tinggi \\
dengan arsitektur Eropa di sekitar \\
Wisma Ranggam. \\
Seorang fotografer berhasil \\
mengambil gambar tugu Wisma sumber bangkatribumewscom \\
Ranggam seperti pada gambar di atas, terdapat tugu kecil yang terdapat \\
disekitar tugu besar. Fotografer tersebut ingin membuat ulang desain \\
gambar tata letak tugu dari arah atas yang tegak lurus dengan permukaan \\
tugu. Manakah dari gambar berikut yang paling baik menunjukan desain \\
ulang yang dibuat fotografer tersebut? jelaskan argumentasimu! (Lingkari \\
salah satu jawaban)
\end{tabular}

a).

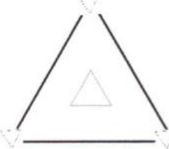

c).

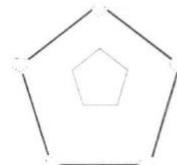

b).
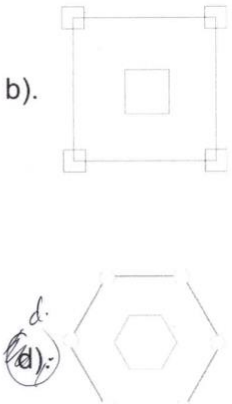

2 Pelabuhan tanjung kalian merupakan pelabuhan penyeberangan yang berada di Muntok Kabupaten Bangka Barat.

Jarak tempuh pelayaran dari

Pelabuhan Tanjung Api-Api

(Palembang) ke Pelabuhan Tanjung

Kalian (Bangka) dengan

menggunakan kapal feri (Ro-ro) dapat

ditempuh perjalanan selama 4 jam.

Jika seseorang menggunakan mobil pribadi naik kapal Fery berangkat dari pelabuhan Tanjung Api-Api pukul 11.00 WIB menuju pelabuhan Tanjung Kalian Muntok hendak ke Pangkalpinang. Perkirakan pukul berapa seseorang tersebut paling cepat meninggalkan pelabuhan Tanjung Kalian Muntok? Jelaskan Argumentasimu. 
DOI: https://doi.org/10.24127/ajpm.v10i4.4369

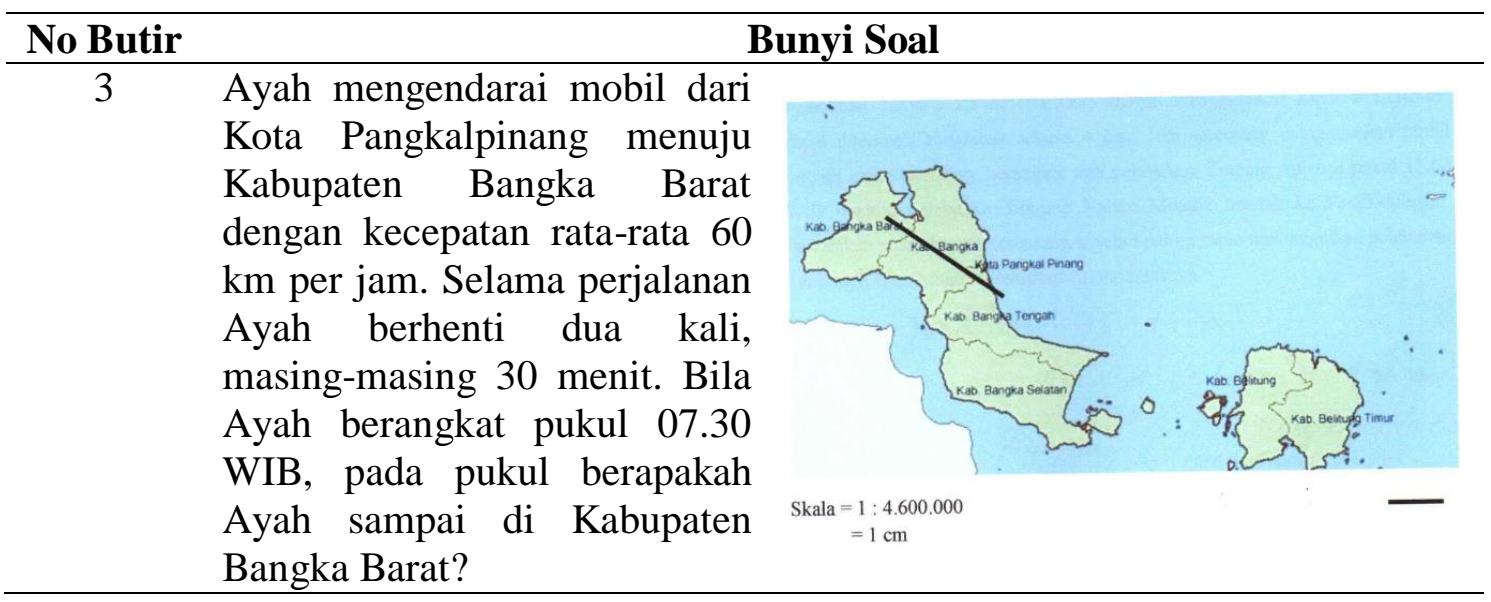

HASIL DAN PEMBAHASAN

Hasil penelitian didapatkan data kemampuan penalaran matematis siswa dalam menyelesaikan soal literasi matematika. Berdasarkan hasil tes yang diberikan kepada 22 siswa dengan soal sebanyak 10 item didapatkan rata-rata penilaian kemampuan penalaran matematika siswa dari masing-masing butir soal seperti pada Tabel 4.

Tabel 4. Hasil Berdasarkan Indikator Kemampuan Penalaran Siswa

\begin{tabular}{ccccccccccc}
\hline \multirow{2}{*}{ Indikator } & \multicolumn{10}{c}{ Nomor Soal } \\
\cline { 2 - 12 } & $\mathbf{1}$ & $\mathbf{2}$ & $\mathbf{3}$ & $\mathbf{4}$ & $\mathbf{5}$ & $\mathbf{6}$ & $\mathbf{7}$ & $\mathbf{8}$ & $\mathbf{9}$ & $\mathbf{1 0}$ \\
\hline I & 65.2 & 40.9 & 33.3 & 33.3 & 50 & 42.4 & 37.9 & 39.4 & 43.9 & 42.4 \\
II & 65.2 & 40.9 & 33.3 & 33.3 & 50 & 42.4 & 37.9 & 39.4 & 43.9 & 42.4 \\
III & 65.2 & 40.9 & 33.3 & 33.3 & 50 & 42.4 & 37.9 & 39.4 & 43.9 & 42.4 \\
IV & 65.2 & 40.9 & 31.8 & 31.8 & 47 & 40.9 & 36.4 & 36.4 & 42.4 & 40.9
\end{tabular}

Keterangan Indikator:

I = Mengajukan dugaan

II = Manipulasi matematika

III = Menyusun bukti atau memberikan alasan

III = Menarik kesimpulan dari pernyataan

Dilihat dari Tabel 3 tampak bahwa indikator kemampuan penalaran matematis tidak semuanya muncul saat siswa mengerjakan soal. Kemampuan penalaran matematis rata-rata paling tinggi muncul dari soal nomor 1 dan 5 . Hal ini menunjukkan bahwa tidak semua siswa mempunyai kemampuan penalaran matematis yang baik.

Setelah dilakukan analisis kemampuan penalaran matematis pada tiap item soal, selanjutnya dilakukan analisis data dengan menghitung persentase dari seluruh indikator kemampuan penalaran matematis siswa.
Berdasarkan analisis data yang dilakukan menunjukkan bahwa semua indikator penalaran matematis siswa mencapai kriteria sangat rendah. Hal ini dapat dilihat pada Tabel 4.

Tabel 4. Rata-rata penilaian indikator kemampuan penalaran siswa

\begin{tabular}{ccc}
\hline Indikator & $\begin{array}{c}\text { Taraf } \\
\text { Penguasaan } \\
(\boldsymbol{\%})\end{array}$ & Kriteria \\
\hline I & 42.88 & Sangat Rendah \\
II & 42.88 & Sangat Rendah \\
III & 42.88 & Sangat Rendah \\
IV & 41.36 & Sangat Rendah \\
\hline
\end{tabular}


DOI: https://doi.org/10.24127/ajpm.v10i4.4369

Dari 10 soal yang diberikan, seperti terlihat pada Tabel 4, dapat disimpulkan bahwa kemampuan setiap indikator penalaran masih rendah. Pembahasan masing-masing indikator penalaran siswa sebagai berikut.

\section{Indikator Mengajukan Dugaan}

Taraf penguasaan siswa pada indikator mengajukan dugaan sebesar $42,88 \%$ dengan kategori sangat rendah. Dari 10 soal yang diberikan, rata-rata siswa tidak mampu mengajukan dugaan, namun indikator ini muncul paling tinggi pada soal nomor 1. Salah satu jawaban siswa pada soal nomor 1 dapat dilihat pada Gambar 1. a).

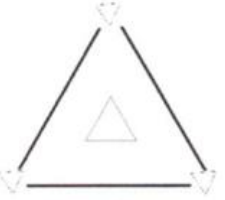

b).

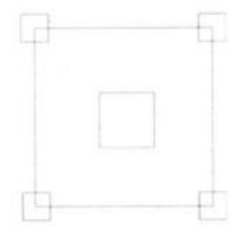

c).

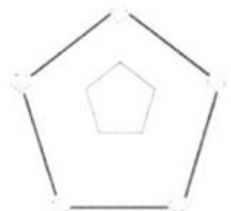

(d):

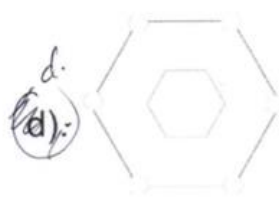

Gambar 1. Contoh jawaban siswa pada indikator 1

Selanjutnya, dilakukan analisis mendalam melalui wawancara seperti berikut.

I : Kemudian ketika menjawab soal apakah ada menggunakan metode menduga-duga?

SI : Ada pak

I Bagaimana itu?

SI Dilihat dari keteranagnnya itu pak. Jadi apa yang ada diketerangannya itu saya jawab yang sesuai aja.

I Kira-kira soal nomor berapa itu?

\section{SI $\quad$ Soal nomor 1 dan 2 \\ I Jadi soal 1 dan 2 dijawab dengan cara menduga-duga. Kalau nomor satu itu bagaimana jawabannya \\ SI Mudah sih jawabannya pak, karena ada keterangannya di situ, jadi saya bisa menjawab soal nomor satu.}

Berdasarkan hasil wawancara, siswa dapat mengajukan dugaan dari informasi yang ada pada soal. Pada soal nomor 1 hasil analisis jawaban siswa sebanyak $65.2 \%$ siswa mampu menduga jawaban yang tepat. Selain itu, siswa menganggap soal mudah karena membutuhkan penalaran tanpa melakukan perhitungan matematis meskipun diperlukan argumentasi. Sedangkan pada soal yang lain dibawah $50 \%$ siswa baru mampu memunculkan indikator mengajukan dugaan disebabkan karena siswa tidak mampu menguraikan informasi dalam soal.

\section{Indikator Manipulasi Matematis}

Pada indikator manipulasi matematis hanya mencapai taraf penguasaan $42,88 \%$. Hal ini berarti kemampuan penalaran siswa pada indikator ini sangat rendah. Siswa kurang mampu melakukan manipulasi matematika dari informasi yang ada dalam soal baik dalam bentuk gambar, simbol, ataupun variabel. Contoh soal dan jawaban siswa terkait indikator manipulasi matematika dapat dilihat pada Gambar 2.

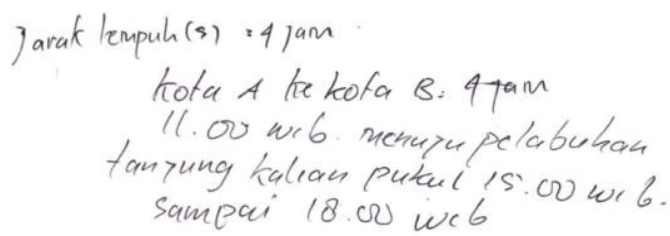

Gambar 2. Soal dan jawaban siswa pada indikator II 
DOI: $\underline{\text { https://doi.org/10.24127/ajpm.v10i4.4369 }}$

\begin{abstract}
Jawaban siswa pada gambar 2 belum menunjukkan indikator manipulasi matematis. Siswa cenderung hanya menuliskan kembali informasi yang ada dalam soal tanpa melakukan manipulasi matematis.
\end{abstract}

Rata-rata pencapaian indikator kemampuan penalaran siswa pada indikator manipulasi matematika mencapai $42,88 \%$, sedangkan untuk soal no 4 ini persentase indikator manipulasi matematika mencapai 33,3\% saja. Hasil analisis jawaban siswa disimpulkan bahwa siswa tidak mampu melakukan manipulasi matematis. Jawaban yang diberikan tidak terstruktur dengan jelas bagaimana langkah penyelesaiannya. Siswa tidak menggunakan berdasarkan algoritma, definisi, dan aksioma dalam menemukan jawaban.

\section{Indikator Menyusun Bukti dan Memberikan Alasan}

Tingkat penguasaan siswa pada indikator menyusun bukti sangat rendah yaitu mencapai $42,88 \%$. Sebagian besar siswa hanya mampu menjawab soal secara langsung tanpa menunjukkan bukti yang dari jawabannya seperti jawaban siswa pada gambar 1 . Meskipun siswa dapat menjawab soal dengan benar, namun siswa tidak mempunyai cukup alasan untuk membuktikan kebenaran jawabannya. Berikut hasil wawancara terhadap salah satu subjek.

I : Alasannya sudah ditulis di lembar jawaban ya? Semua soal sudah diberikan buktibukti?

S2 : Sudah pak. Semua soal saya beri alasan dan bukti sesuai dengan logika saya.

I : Oke untuk pertanyaan ke 4. Apakah ada memberikan kesimpulan pada setiap soal?
Apakah ada kendala dalam memberikan bukti dan alasan soal? Pada nomor berapa?

S2 : Menurut saya, nomor 1. Karena kita kan tidak merasakan posisi fotografer itu. Jadi terdapat kendala untuk mencari alasan atau bukti bentuk paling baik desain ulang dari fotografer tersebut. Jika hanya menggunakan opsi itu sangat mudah dan bisa menduga-duga. Tapi menggunakan alasan kita harus berpikir secara logis alasannya apa dan tidak bisa menduga-duga

I : Oke jadi, soal nomor satu tadi itu terdapat kendala kalau tidak ada gambar tadi. Kalau ada gambar bisa membantu kamu untuk menjawab. Hanya saja di alasan tadi tidak ada alasan secara matematika untuk membuktikan bahwa itu benar. Tapi yang paling mendekati itulah alasannya.

\section{S2 : Iya pak.}

Dapat disimpulkan bahwa siswa mengalami kesulitan dalam menunjukkan bukti paling baik dari permasalahan tentang posisi fotografer. Meskipun siswa dapat menjawab dengan tepat berdasarkan dari pilihan jawaban yang diberikan, namun siswa kesulitan menunjukkan bukti karena menggunakan dugaan dari pilihan jawaban yang diberikan Selain itu, siswa cenderung langsung menjawab soal menggunakan penalaran dan logika.

\section{Indikator Menarik Kesimpulan dari Pernyataan}

Pada indikator ke IV, taraf penguasaan dari penalaran matematis sangat rendah dibandingkan dengan 
indikator I, II, dan III. Rata-rata taraf penguasan pada indikator ini hanya mencapai 41,36 \%. Rata-rata siswa tidak memberikan kesimpulan dari jawaban yang diberikan. Salah satu contoh jawaban siswa dapat dilihat pada Gambar 3.

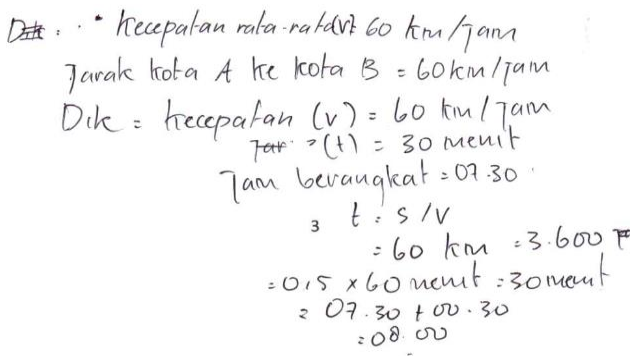

Gambar 3. Soal dan contoh salah satu jawaban siswa pada indikator IV

Berdasarkan Gambar 3, ditunjukkan bahwa siswa tidak memberikan kesimpulan dari jawaban yang diberikan. Siswa hanya menjabarkan langkah penyelesaian hingga diperoleh hasil 08.00 dan pada akhirnya hasil tersebut kurang tepat. Hal disebabkan karena siswa tidak terbiasa menyimpulkan jawaban secara tertulis saat mengerjakan soal matematika. Siswa hanya menggunakan penalaran tanpa menggunakan rumus dan menarik kesimpulan seperti hasil wawancara berikut.

Hasil wawancara salah satu subjek berikut terkait dengan respon menjawab soal

I : Oke yang terakhir, untuk mengerjakan soal ini, apakah membutuhkan penalaran atau biasa-biasa aja?

S3 : Membutuhkan nalar sih pak. Kalau nalar tidak jalan dan hanya mengandalkan rumus atau cara pencarian lain kita tidak bisa menyelesaikan soal ini. Karena soal ini seperti menyangkut masalah yang terdapat di kehidupan seharihari

I : Jadi ini membutuhkan penalaran yak arena terkait dengan kehidupan sehari-hari. Kita tidak bisa mengandalkan rumus saja. Kira-kira soal nomor berapa? Apa pertanyaannya?

S3 : Soal nomor tiga pak. Pertanyaannya ayah mengendara mobil dari kota pangkalpinang ke kabupaten Bangka Barat dengan kecepatan rata-rata $60 \mathrm{~km} / \mathrm{jam}$. Selama perjalanan ayah berhenti dua kali dengan masing-masing 30 menit. Bila ayah berangkat pukul 07.30 WIB pada pukul berapa ayah sampai di kabupaten Bangka Barat. Jadi ini soal kehidupan sehari-hari pengalaman saya, disini terdapat soal seperti diketahui, skala $1: 4.600 .000$ kemudian dibawahnya $1 \mathrm{~cm}$. jawaban saya 4.600 .00 dikalikan dengan $1 \mathrm{~cm}$ jadi 4.600.000 kemudian diubah menjadi Km sehingga $46 \mathrm{~km}$. pada soal diketahui kecepatan rata-rata adalah $60 \mathrm{~km} / \mathrm{jam}$. Jadi $46 \mathrm{~km}$ tidak sampai satu jam. Sehingga waktu yang diprukan hanya 45 menit. Jika berangkat pukul 7.30 WIB dan dua kali berhenti yaitu 30 menit terhitung 1 jam. 7.30 ditambah 1 jam jadi terdapat pada jam 8.30 WIB kemudian ditambah 45 menit lagi. Jadi ayah sampai pada jam 9.15 WIB.

I : Oke, jadi itu soal nomor 3 ya. Itu soalnya baru pertama kali mengerjakan soal seperti ini? 
DOI: https://doi.org/10.24127/ajpm.v10i4.4369

\section{S3 : Iya pak. Karena kalau di soal- soal sebelummnya dikasih tau berapa jarak kotanya. Tapi di sini tidak dicantumkan. Sehingga soal ini membutuhkan penalaran.}

Hasil wawancara menunjukkan bahwa siswa hanya menggunakan penalaran untuk menjawab soal. Siswa tidak mampu memberikan kesimpulan dari informasi yang diberikan soal.

Dari hasil penelitian disimpulkan bahwa kemampuan penalaran siswa dalam menyelesaikan soal literasi matematika kontekstual masih rendah. Penyebab sangat rendahnya kemampuan penalaran matematis siswa diataranya siswa tidak memahami informasi dari soal dengan baik. Sejalan dengan penelitian (Anisah et al., 2011) siswa kesulitan untuk mengidentifikasi permasalahan dan otomatis kesulitan juga dalam menentukan cara matematis yang relevan untuk menyelesaikan masalah. Selain itu siswa merasa kurang persiapan belajar dalam mengerjakan soal karena tes diberikan secara langsung tanpa diberitahukan sebelumnya. Disamping itu, siswa tidak terbiasa mengerjakan soal-soal yang menuntut kemampuan penalaran serta kurangnya penguasaan terhadap konsep materi yang telah lama dipelajari sebelumnya. Hal ini sejalan dengan hasil penelitian (Asdarina \& Ridha, 2020) bahwa rendahnya kemampuan penalaran siswa disebabkan karena tidak terbiasa diberikan soal yang sedikit rumit dan memerlukan tingkat pemecahan masalah yang tinggi.

Dari hasil taraf penguasaan yang sangat rendah pada masing-masing indikator, maka diperlukan upaya untuk dapat meningkatkan kemampuan penalaran matematis siswa. Salah satu upaya yang dapat dilakukan adalah membiasakan siswa mengerjakan soalsoal literasi matematis kontekstual yang mengasah kemampuan penalaran siswa. Sejalan dengan penelitian (Lestari et al., 2019) bahwa rata-rata N-Gain kemampuan penalaran matematis siswa yang memperoleh pembelajaran matematika dengan pendekatan pendidikan matematika realistik lebih tinggi dibandingkan siswa yang memperoleh pembelajaran matematika dengan pendekatan konvensional

\section{KESIMPULAN DAN SARAN}

Berdasarkan hasil penelitian dan analisis data maka disimpulkan bahwa tingkat penguasaan kemampuan penalaran matematis siswa sangat rendah dari semua indikator kemampuan penalaran matematis. Penyebab sangat rendahnya kemampuan penalaran matematis siswa karena tidak terbiasa mengerjakan soal penalaran, kurang menguasai konsep, dan sulit dalam memahami soal. saran untuk para guru agar membahas banyak soal berpikir tingkat tinggi khususnya kemampuan penalaran di sekolah. Penelitian selanjutnya dapat membuat media pembelajaran untuk meningkatkan kemampuan penalaran matematis SMA dengan menggunakan konteks daerah siswa.

\section{DAFTAR PUSTAKA}

Alim, J. A., Fauzan, A., Arwana, I. M., \& Musdi, E. (2020). Model of Geometry Realistic Learning Development with Interactive Multimedia Assistance in Elementary School. Journal of Physics: Conference Series, 1471(1), 1-8. https://doi.org/10.1088/17426596/1471/1/012053

Amir-Mofidi, S., Amiripour, P., \& Bijan-Zadeh, M. H. (2012). 
DOI: https://doi.org/10.24127/ajpm.v10i4.4369

Instruction of Mathematical Concepts through Analogical Reasoning Skills. Indian Journal of Science and Technology, 5(6), 2916-2922. https://doi.org/https:// doi.org/10.17485/ijst\%2F2012\%2 Fv5i6\%2F30485

Anisah, Zulkardi, \& Darmawijoyo. (2011). Pengembangan Soal Matematika Model Pisa Pada Konten Quantity Untuk Mengukur. Jurnal Pendidikan Matematika (JPM), 5(1), 1-15. https://media.neliti.com/media/pu blications/121613-IDpengembangan-soal-matematikamodel-pisa.pdf

Asdarina, O., \& Ridha, M. (2020). Analisis Kemampuan Penalaran Matematis Siswa Dalam Menyelesaikan Soal Setara Pisa Konten Geometri. Numeracy, 7(2), 192-206. https://doi.org/10.46244/numerac y.v7i2.1167

Ayuningtyas, W., Mardiyana, \& Pramudya, I. (2019). Students' responses to the test instruments on geometry reasoning ability in senior high school. Journal of Physics: Conference Series, 1265(1).

https://doi.org/10.1088/17426596/1265/1/012015

Dewi, D. K., Khodijah, S. S., \& Zanthy, L. S. (2020). Analisis Kesulitan Matematik Siswa SMP pada Materi Statistika. Jurnal Cendekia: Jurnal Pendidikan Matematika, 4(1), 1-7. https://doi.org/10.31004/cendekia. v4i1.148

Duval, R. (2014). Commentary: Linking epistemology and semio-cognitive modeling in visualization. $Z D M$, $46(1)$,

159-170. https://doi.org/10.1007/s11858013-0565-8

Fachrudin, A. D., Ekawati, R., Kohar, A. W., Widadah, S., Kusumawati, I. B., \& Setianingsih, R. (2019). Ancient China history-based task to support students' geometrical reasoning and mathematical literacy in learning Pythagoras. Journal of Physics: Conference Series, 1417(1). https://doi.org/10.1088/17426596/1417/1/012042

Hahn, A. J. (2020). Basic Calculus of Planetary Orbits and Interplanetary Flight: The Missions of the Voyagers, Cassini, and Juno. Springer Nature. https://doi.org/https://doi.org/10.1 007/978-3-030-24868-0

Hendriana, H., Eti Rohaeti, E., \& Hidayat, W. (2017). Metaphorical thinking learning and junior high school teachers' mathematical questioning ability. Journal on Mathematics Education, 8(1), 5564.

https://doi.org/10.22342/jme.8.1.3 614.55-64

Janah, S. R., Suyitno, H., \& Rosyida, I. (2019). Pentingnya Literasi Matematika dan Berpikir Kritis Matematis dalam Menghadapi Abad ke-21. PRISMA, Prosiding Seminar Nasional Matematika, 2, 905-910.

https://journal.unnes.ac.id/sju/inde x.php/prisma/article/download/29 305/12924

Leksmono, A., Sunardi, Prihandoko, A. C., \& Murtikusuma, R. P. (2019). Students' creative thinking process in completing mathematical PISA test concerning space and shape. Journal of Physics: Conference 
DOI: https://doi.org/10.24127/ajpm.v10i4.4369

Series, $\quad 1211(1)$.

https://doi.org/10.1088/1742-

6596/1211/1/012073

Lestari, I., Prahmana, R. C. I., \& Wiyanti, W. (2019). Jurnal inovasi pendidikan dasar. Jurnal Inovasi Pendidikan Dasar, 5(1), 31-44.

http://jipd.uhamka.ac.id/index.php /jipd/article/view/48

Miles, M. B., \& Huberman, A. M. (1992). Analisis Data Kualitatif. Terjemahan Tjetjep Rohendi Rohidi. Penerbit Universitas Indonesia.

OECD. (2013). PISA 2015 Mathematics Framework. OECD publishing.

OECD. (2018). Programme for International Student Assessment (PISA)result from 2018. Programme for International Student Assessment (PISA) Result from PISA 2018. OECD publishing.

OECD. (2019). PISA 2018 assessment and analytical framework. OECD publishing.

Ojose, B. (2011). Mathematics literacy: Are we able to put the mathematics we learn into everyday use. Journal of Mathematics Education, 4(1), 89100.

Putra, Y. Y., \& Vebrian, R. (2019). Literasi

Matematika (Mathematical Literacy) Soal Matematika Model Pisa Menggunakan Konteks Bangka Belitung. Deepublish.

Putra, Y. Y., Zulkardi, Z., \& Hartono, Y. (2016a). Pengembangan Soal Matematika Model PISA Konten Bilangan untuk Mengetahui Kemampuan Literasi Matematika Siswa. Jurnal Elemen, 2(1), 14. https://doi.org/10.29408/jel.v2i1.1
75

Putra, Y. Y., Zulkardi, Z., \& Hartono, Y. (2016b). Pengembangan Soal Matematika Model PISA Level 4, 5, 6 Menggunakan Konteks Lampung. Kreano, Jurnal Matematika Kreatif-Inovatif, 7(1), $10-16$. https://doi.org/10.15294/kreano.v $7 \mathrm{i} 1.4832$

Schoevers, E. M., Leseman, P. P. M., \& Kroesbergen, E. H. (2020). Enriching Mathematics Education with Visual Arts: Effects on Elementary School Students' Ability in Geometry and Visual Arts. International Journal of Science and Mathematics Education, 18(8), 1613-1634. https://doi.org/10.1007/s10763019-10018-z

Semilarski, H., Laius, A., \& Rannikmäe, M. (2019). Development of estonian upper secondary school students' biological conceptual understanding and competences. Journal of Baltic Science Education, 18(6), 955-970. https://doi.org/10.33225/jbse/19.1 8.955

Trajuningsih, E. (2015). Proses berpikir matematis siswa SMAN 8 Malang dalam menyelesaikan masalah matematika dan scaffolding (Masters th). Universitas Negeri Malang.

Wijaya, T. T., Mutmainah, I. I., Suryani, N., Azizah, D., Fitri, A., Hermita, N., \& Tohir, M. (2021). Nineth grade students mistakes when solving congruence and similarity problem. Journal of Physics: Conference Series, 2049(1). https://doi.org/10.1088/1742- 
DOI: https://doi.org/10.24127/ajpm.v10i4.4369

6596/2049/1/012066

Wijaya, T. T., Ying, Z., Chotimah, S., Bernard, M., Zulfah, \& Astuti. (2020). Hawgent dynamic mathematic software as mathematics learning media for teaching quadratic functions. Journal of Physics: Conference Series, 1592(1). https://doi.org/10.1088/17426596/1592/1/012079 